PALAVRAS. Revista de Epistemología, Metodología y Ética del Psicoanálisis

ISSN: 2468-9831

www.revistas.unlp.edu.ar/palavras

palavras@outlook.com.ar

Argentina

\title{
UN CRUCE METODOLÓGICO: ANÁLISIS DISCURSIVO DE DOS SERIES DE SUEÑOS REFERIDAS EN SESIONES PSICOANALÍTICAS
}

DOI $10.24215 / 24689831 \mathrm{e} 023$

\section{Celeste Labaronnie}

\begin{abstract}
This article is based on the enunciation theory and conducts a discourse analysis (DA) of two dreamseries related by two clients, along several years of psychoanalytical treatment. Discourse analysis is here considered as an interdisciplinary methodology, with potential value for psychoanalysis, and vice versa. We analyze the enunciative categories of person, predominant illocutionary attitude (narrated world/commented world), lexical appreciative charges and its interaction with the associative field, and some meaningful examples of modalization. This work allows for establishing that psychoanalysis, and especially dream theory, has some contribution to offer to DA regarding the third person category, whereas DA turned out to be valuable for displaying issues such as verbal tenses modifications and associative fields amplitude; which even if they concern psychoanalysts as well, they may not be so evident as they become in a meticulous DA.
\end{abstract}

Key words: Discourse Analysis; Psychoanalysis; Dream; Enunciative Categories
Este trabajo parte de la teoría de la enunciación y realiza un análisis discursivo (AD) de dos series de sueños relatadas por dos pacientes, a lo largo de varios años de tratamiento psicoanalitico. Se toma al análisis del discurso como metodología interdisciplinaria, de valor potencial para el psicoanálisis y viceversa. Se analizan las categorias enunciativas de persona, actitud de locución predominante (mundo narrado/mundo comentado), cargas valorativas del léxico y su articulación con el campo asociativo, y algunos ejemplos significativos de modalización. El trabajo realizado permite afirmar que el psicoanálisis, y en especial la teoría del sueño, tiene algo para aportar al $\mathrm{AD}$ en lo concerniente a la categoría de la tercera persona, mientras que el $\mathrm{AD}$ se muestra muy enriquecedor para visualizar cuestiones como la modificación de tiempos verbales y la amplitud de los campos asociativos; que, si bien también son materia del psicoanalista, tal vez no sean tan evidentes como lo son en un $\mathrm{AD}$ minucioso. Palabras claves: Análisis del Discurso; Psicoanálisis; Sueño; Categorías Enunciativas

\section{Cómo citar este artículo:}

Labaronnie, C. (2018). Un cruce metodológico: análisis discursivo de dos series de sueños referidas en sesiones psicoanalíticas. Palavras. Revista de Epistemología, Metodología y Ética del Psicoanálisis, 4, 25-51. Recuperado de www.revistas.unlp.edu.ar/palavras 


\section{UN CRUCE METODOLÓGICO: ANÁLISIS DISCURSIVO DE DOS SERIES DE SUEÑOS REFERIDAS EN SESIONES PSICOANALÍTICAS}

\section{Celeste Labaronnie*}

\section{Introducción}

En el presente trabajo nos proponemos analizar discursivamente una serie de sueños, relatados en sesión por dos pacientes, cuyo psicoanálisis conduje durante varios años. Los llamaremos "A." y "P.". Por lo tanto, emprendemos una tarea interdisciplinaria (Arnoux, 2006), aplicando la herramienta teóricometodológica del análisis del discurso a un material recogido de sesiones psicoanalíticas. A su vez, nos proponemos articular este análisis discursivo (en adelante $\mathrm{AD}$ ) con conceptos extraídos del psicoanálisis, tal como lo propone Arnoux para la aplicación del AD a otro campo del saber, del cual no debe desconocerse ni omitirse su teoría.

Entonces, nuestro marco teórico está constituido, por un lado, por la Teoría de la Enunciación, inaugurada por Émile Benveniste y continuada por diversos autores -algunos de los cuales iremos mencionando a lo largo del escrito-, y por otro lado, por el psicoanálisis lacaniano, como continuación y ampliación del descubrimiento freudiano.

En cuanto a nuestro corpus de análisis, cabe aclarar que el recorte de una serie de sueños, dejando por fuera muchos otros que ocurren durante un tratamiento, responde únicamente a un objetivo de investigación. De la misma manera, hemos optado por excluir las asociaciones surgidas a partir de la interrogación de los elementos de cada sueño, las cuales, partiendo del método freudiano de asociación libre, abren un campo de análisis amplísimo, que

\footnotetext{
* Facultad de Psicología, Universidad Nacional de La Plata. Mail: celelab@gmail.com
} 
excedería las posibilidades de un $\mathrm{AD}$ y se convertiría en un relato del caso en su totalidad.

No obstante, conviene recordar que las modificaciones que podremos apreciar entre un sueño y otro, son fruto del trabajo realizado en sesión, consistente en la apertura de nuevos sentidos, que van corroyendo la ambición de univocidad propia del discurso consciente. Apertura que no implica interpretaciones que "engrosen" el sentido; nos abocamos más bien a interrogar los sentidos coagulados que porta el analizante y a desarmar las interpretaciones ya existentes, mediante el uso del equívoco, la cita y el chiste, entre otros. Se espera que con este trabajo, los mandatos superyoicos se alivianen y den lugar a elecciones subjetivas singulares, que llamamos "acto".

Las categorias enunciativas que analizamos son: la inscripción de las personas en el discurso, la actitud de locución predominante (mundo narrado/mundo comentado) y las cargas valorativas del léxico -tomando de Kerbrat-Orecchioni (1986/1997) la nominación de "subjetivemas"-, en su articulación con la noción de "campo asociativo". También mencionamos algunos ejemplos significativos de modalización.

Para cada una de estas categorias, es necesario introducir algunas articulaciones con la especificidad del discurso psicoanalítico y sus conceptos clave. Muchas de esas aclaraciones están orientadas a lectores potenciales que no provengan del ámbito del psicoanálisis y estén interesados en otras aplicaciones del AD. Sin embargo, por tratarse de un AD, hemos omitido todo análisis de las recurrencias fonológicas, aspecto al que el psicoanálisis da mucha importancia.

\section{Construcción del corpus de análisis}

Para conformar nuestro corpus de análisis, tomamos en consideración el hecho de que un objeto de estudio "siempre es el resultado de una construcción que corresponde al objetivo y a las hipótesis que se da el que analiza. [...] El corpus 
es el acto metodológico por el cual se concretiza el objeto como objeto de análisis" (Charaudeau, 2000: 41). Por lo tanto, recortamos de un abundante material clínico, una serie de sueños que responden a lo que Freud llamó "continued story" (Freud, 1900/2001: 113). Al respecto, explica que en algunos análisis o en algunos tramos de los mismos, los sueños son capaces de anudarse unos con otros en la diacronía, tomando como centro un elemento que en el sueño anterior se rozaba de pasada y así sucesivamente. Freud remarca que se establece de ese modo una separación entre la vida onírica y la de vigilia. Utilizaremos dicha disociación para captar las modificaciones que va experimentando la posición subjetiva a lo largo de cierto tiempo de tratamiento y la forma en que esos cambios se ven reflejados en la posición enunciativa.

Respecto a los relatos de sueños seleccionados, resta señalar que corresponden a lo que Freud llamó "contenido manifiesto" (por oposición a los pensamientos latentes que surgen tras la asociación), que por su carácter esquemático, permiten más fácilmente un $\mathrm{AD}$. Dicho contenido consiste en el relato del sueño que emprende el analizante en sesión (aunque es probable que algunos detalles se hayan perdido por la dificultad de transcribir al ritmo del discurso oral).

La riqueza del material estará, entonces, en los cambios que podremos notar de un sueño a otro, dejando por fuera numerosos desarrollos que partirían de las asociaciones del soñante (sólo en unos pocos casos haremos mención a las mismas). Perderemos, por lo tanto, la multiplicidad de significaciones que cada uno de los elementos adquiere para ese analizante, pero ganaremos en material comparativo, pudiendo apreciar modificaciones discursivas que se manifiestan en estos sueños de forma muy clara.

A su vez, para seleccionar algunos sueños y dejar por fuera otros, nos vimos obligados a operar un recorte, partiendo de la elección de un significante que pudiera constituir el hilo conductor de una cadena de sueños. Podría haber sido otro $\mathrm{y}$, en ese caso, la serie habría sido diferente y habría guiado a otro 
recorrido, puesto que el encadenamiento onírico responde a la misma estructura arborescente que las asociaciones a partir de un único sueño.

En este caso, hemos elegido elementos significantes que adquieren, para cada uno de los analizantes, una carga valorativa ligada a la angustia: el mar, en uno de los casos, y la oscuridad, en el otro. Ambos admitirian múltiples lecturas y, de hecho, recibieron diversas interpretaciones por parte de los analizantes en distintos momentos de la cura. Pero no los elegimos por ello, sino por su insistencia, que denota la condensación de un valor subjetivo central, que se desgasta pero no se agota en la serie de sueños que aquí presentaremos. Es decir que podrán seguir arrojando otros sentidos a partir de nuevos sueños, donde se los vincule con otros significantes y se los introduzca en contextos diferentes.

\section{Subjetivemas y campos asociativos}

Como sabemos, los subjetivemas, en tanto hacen referencia a la carga axiológica o afectiva de las unidades léxicas, frases y expresiones, son una de las formas en que se vehiculiza la posición del sujeto hablante respecto a los objetos de su discurso. Según Katherine Kerbrat-Orecchioni, "toda unidad léxica es, en cierto sentido, subjetiva, dado que las "palabras" de la lengua no son jamás otra cosa que símbolos sustitutivos e interpretativos de las "cosas"" (1986/1997: 91-92). Esta aclaración nos permite resaltar la inevitable valoración subjetiva de todo elemento de un relato onírico.

En función de nuestro objeto de análisis, consideramos especialmente útil para la exploración de las valoraciones, la diferencia entre "campo asociativo" y "campo léxico", tal como la desarrolla Adalberto Ghio (2012). Según el autor, la noción de "campo asociativo", introducido por Charles Bally (1940), permite enfocar el modo en que un signo lingüístico se encuentra en el centro de todo un campo asociativo, con el cual mantiene relaciones de similitud $o$ contingencia tanto de los significados como de los significantes. Se trata, entonces, de un hecho de discurso, más que de relaciones estructurales 
propias de la lengua. "A diferencia de los campos léxicos, que se organizan por medio de los semas opositivos o de los rasgos distintivos del significado léxico, los campos asociativos se fundan en relaciones que involucran las cosas designadas" (Ghio, 2012: 192). Por lo tanto, no dependerán de las relaciones constantes propias de la lengua, sino del contexto de referencia y de la práctica discursiva específica.

El modo en que un mismo objeto discursivo es nombrado mediante designaciones neutras y axiológicas, constituye un paradigma designacional. $\mathrm{Su}$ importancia para nuestro corpus de análisis reside en poder identificar cómo las diversas designaciones de un mismo objeto destacan diferentes atributos del mismo, según el punto de vista desde el cual se lo considere.

\section{Objetos de discurso y subjetivemas nominales}

Comenzaremos analizando las variaciones de los objetos centrales "oscuridad" y "mar" -señalamos en negrita sus principales apariciones en el corpus, ver anexo-, cuya carga valorativa puede deducirse del co-texto donde hacen su primera aparición ("De chico soñaba con mitos urbanos, como La Llorona y con la oscuridad" y "Siempre sueño con el mar de noche. El agua sucia, marrón. Me atrapa el mar, pero termino saliendo. Me escapo o corro"). Se evidencia en la enunciación la carga angustiante de ambos objetos para los analizantes en cuestión, además de que los vinculan con temores de infancia y miedos recurrentes, respectivamente.

En los textos de Freud, los sueños aparecen muchas veces interpretados en clave fálica y edípica. Con Lacan, si bien sabemos que esas interpretaciones son posibles, preferimos tomarlas como una lectura más, entre otras, que no es necesario explicitar, y en cambio, llamamos "interpretación" a una práctica que procede por la vía del equívoco o el chiste hacia el sinsentido. Es decir que la interpretación se convierte en una des-interpretación de los sentidos fantasmáticos recurrentes. Estas aclaraciones tienen por finalidad explicitar al lector las razones por las cuales nuestra interpretación de los subjetivemas en 
este escrito intentará ser lo más liviana posible, apuntando a resaltar las formas recurrentes, más que los sentidos posibles.

Entonces, atendiendo al aspecto formal de los subjetivemas nominales, podemos decir que encontramos en P., mayormente sueños donde el objeto oscuridad es presentado directamente a través del sustantivo homónimo (en 1, 3, 6, 7 y 18), aunque también se lo indica a través de su antónimo (el "espacio de luz" en 19) y la negación de este último (la "luz que no se prende", en 3; el "farol al que faltaba la luz").

Además, esta serie de sueños presenta abundantes alusiones a la oscuridad a través de un campo asociativo constituido por elementos tales como la boca de tormenta (en 8), los vórtices (en 13) y el túnel de barro (en 15). Es interesante reparar en que, tratándose de sueños, la elección de esas alusiones es a veces muy personal, como es el caso de "la asfixia" (en 12), que apunta tal vez a la oscuridad de la muerte, y el "tipo ciego" (en 9), donde la oscuridad se hace presente a través de la identificación.

Por otro lado, en casi todos los sueños de A. con que hemos conformado esta serie, encontramos la recurrencia del sustantivo "mar". Entonces, es más interesante analizar las designaciones que aluden o reemplazan al mar en los relatos oníricos en que el término no aparece de forma explícita. En algunos de ellos, encontramos diversas transformaciones del objeto "mar", que podriamos considerar pertenecientes a un mismo campo léxico, aunque con una nota bastante singular en su elección ("piletones de agua sucia", en 8; "poquita agua", en 15; "lago", en 16 y "bajo el agua", en 17).

Como puede apreciarse, estas transformaciones no son azarosas, sino que contribuyen a efectos de sentido muy precisos: mientras que los piletones de agua sucia ofrecen una imagen desagradable y angustiante, hay una notoria reducción operada por los últimos tres sueños de la serie, que convierten el mar en un lago, un poquito de agua no amenazante y, finalmente, un espacio habitable (bajo el agua). Decimos "reducción" porque lo atemorizante se ve 
circunscripto y progresivamente limitado; aunque en el último sueño vuelve a presentarse como algo espacioso, pero ya no angustiante, puesto que la soñante ha encontrado un modo de habitar allí, disfrazada.

Desde el psicoanálisis, esta problemática podría pensarse a partir de la interrogación de Lacan "¿Qué me es más próximo [...] que ese núcleo de mí mismo que es el del goce, al que no oso aproximarme?" (1959-60/2007: 225). Es decir, el mar, que aquí representa un objeto angustiante, pero de alguna manera también íntimo, profundamente conocido por esta analizante, pasa a ser para ella un lugar soportable, gracias a un modo singular de habitarlo: el disfraz -que no debemos tomar literalmente en este caso-. Para lo irreductible de cierta porción de ese goce parasitario, Lacan (1975-76/2009) propuso que la cuestión analítica debía orientarse hacia la invención de un saber-hacer con él. De ahí la importancia de las transformaciones que vemos en estos sueños respecto a estos objetos centrales.

Por otro lado, en el sueño 4, el mar es reemplazado por pasto a partir de una relación de similitud dentro de un mismo campo asociativo (la soñante señala que se encontraba en una isla emplazada sobre lo que bien podríamos denominar "un mar de pasto" y que en el sueño pensaba "ya no es líquido, no te hundís si pisás"). También, de acuerdo al campo asociativo singular de esta analizante, en los sueños 5 y 7 el mar es aludido metonímicamente, ya que no se lo nombra pero sí se menciona la presencia de un barco. En el último caso, y tal vez para que no quedaran dudas respecto a que se estaba ganando distancia con lo angustiante del mar, al barco se lo dota directamente de ruedas, con un efecto cómico, tal vez alusivo a la frase "marchar sobre ruedas".

También encontramos interesantes formas de aparición del objeto "mar" a través de la modalización. En un caso, la duda, como modalidad lógica del enunciado: "no sé si era mar..." (sueño 9); y en otro, una modalización apreciativa del enunciado que sorprende, porque introduce una ruptura con el sentido negativo que se venía dando al objeto central: "yo me lamentaba de no poder ir al agua" (en 10). La modalización del sueño 9 es sumamente 
importante, ya que desde Freud reconocemos los elementos dudosos del sueño como aquellos que encierran mayor enigma y defensa frente a los pensamientos asociados a dicho elemento.

Continuando con los subjetivemas nominales, es interesante comparar la serie de sueños de P. y de A. respecto a la adjetivación del elemento recurrente.

Vemos que P. transforma el sustantivo "oscuridad" en una serie de adjetivos que utiliza para calificar a otros objetos. En algunos casos, su aparición es directa ("habitación oscura" en 2, "arbustos oscuros" y "plaza oscura" en 5, "zona oscura" y "edificio oscuro" en 8, "remolinos oscuros" en 13 y "todo oscuro" en $3,4,11,17$ y 20), mientras que en otros, lo hace a través de su opuesto ("zona iluminada" en 8, "ciudad bien iluminada" en 10, "patio interno iluminado" en 16 y "cuarto iluminado" en 20).

En el caso de A. en cambio, es el mar -y sus equivalentes- el que será calificado a través de distintos adjetivos, que irán modificando su aparición en los sucesivos sueños. Tenemos así el "marrón" y el "sucio" que calificarán al mar, al agua y las olas (en 1, 8, 11); el "mar celeste" (de 2, 3 y 10); y también "transparente" (en 10). En 15, lo marrón es desplazado del agua a las montañas, mientras que en 13, se opone el "mar abierto" con el "agua entre dos montañas". Es evidente cómo ambas transformaciones responden a una reducción de la representación angustiante (lo marrón pasa a celeste y luego a transparente, por ejemplo). Obsérvese que "celeste" coincide con el nombre de la analista, constituyendo lo que Lacan llamó el "significante cualquiera" en el algoritmo la transferencia (1967/2012): rasgo que el analizante desprende de la persona o el nombre de su analista, para articularlo en alguna formación del inconsciente (sueño, lapsus, chiste) con el síntoma que identifica el padecimiento por el que demanda un análisis.

Por otra parte, en 12, 13, y 14 encontramos lo lejano puesto en relación con el mar (el mar "a lo lejos"), que podemos suponer vinculado a la distancia que la analizante fue ganando respecto a su angustia en el tiempo de tratamiento, una 
distancia que es también reducción del goce amenazante (así como el elemento acuoso se va reduciendo de "mar abierto" a "lago" o "poquita gua").

En 16, podemos apreciar cómo el agua entra en un nuevo campo semántico, ligado a lo agradable y amigable ("un lago entre montañitas de tierra. Yo estaba nadando. Era un ambiente de amigos"), aunque sin dejar de estar presente cierta amenaza ("Iba mirando que jugando no me quisieran hundir"). Ese cambio es inaugurado por la modalización que mencionábamos anteriormente ("yo me lamentaba de no poder ir al agua", en 10) y llevado a su máxima expresión en el último sueño de la serie, donde la soñante habita bajo el agua con un disfraz de pez.

Por otra parte, el "todo oscuro" que aparece en varios sueños de P., sufre también una reducción, ya que en 3,4 y 11 se lo menciona en relación a un todo absoluto, mientras que en 17 y 20, se lo nombra como "todo", pero restringiéndolo en un caso al exterior (lo que se veía por las ventanas, en 17) y en otro, al cuarto de la madre (en 20).

También es relevante la referencia a "lo oscuro" en los sueños de P. (en 12 y 17) como voz neutra, a medio camino entre la oscuridad sustantivada y los objetos que son adjetivados como "oscuros". Al nombrarlo así, también se lo personifica ("lo oscuro a lo lejos me agarraba", en 12).

Igualmente destacable es la recurrencia del sinónimo "negro", que aparece en relación con objetos concretos ("gato negro" en 4, "auto negro" en 10, "túnel todo negro" en 15, "nube negra" en 19) y adjetivos similares, como "nublado, tipo sepia" (en 11). Se ve entonces cómo el campo léxico habilita numerosas derivaciones.

Como puede apreciarse, los desplazamientos y transformaciones de los elementos léxicos son sumamente abundantes en el material onírico de ambos analizantes (lo que es una característica esencial del sueño). 
En definitiva, tanto en P. como en A. encontramos una significación de reducción, vehiculizada a través de elementos lingüísticos muy variados: desde el uso de sinónimos hasta la inclusión de un mismo elemento en un campo semántico nuevo, pasando por una adjetivación que va de valores negativos a otros más matizados, llegando a alcanzar incluso valores positivos.

\section{Noción psicoanalitica de "acto" y subjetivemas verbales}

Como dijimos anteriormente, en sesión no realizamos interpretaciones del tipo "eso que usted sueña simboliza tal cosa"; porque eso genera resistencia y es una reducción innecesaria de la amplitud de sentidos posibles. A nuestro parecer, Freud incurría a veces en este forzamiento, y esa fue la vía que tomó cierta corriente del psicoanálisis ${ }^{1}$.

Lacan abogó más por otro modo de trabajo, tomado también de Freud, que avanza de un modo menos explícito, más bien sugerente y alusivo, dando central importancia a no reducir todo a significaciones. Para quienes seguimos su enseñanza, el trabajo con un sueño en sesión consiste en pedir asociaciones con algunos o varios elementos del relato y resaltar los significantes importantes del material mediante la cita. Por lo tanto, alcanza con tomar, por ejemplo, alguna acción central del sueño y citarla fuera de contexto (decir algo como: "así que algo se rompía..."), en lugar de dar rápidamente a esa ruptura una posible relación con sucesos de la vida cotidiana del analizante. En su lugar, pedimos que sea él quien ensaye alguna interpretación.

Hecha esta aclaración, pasamos a revisar los verbos presentes en nuestro corpus, algunos de los cuales revisten gran importancia.

En primer lugar, encontramos en los sueños de P. la alternancia de acciones relacionadas con el oscurecimiento y la iluminación ("tiraba un fósforo para iluminar" en 2, "quería prender una luz, pero no se prendía" en 3, "se oscureció

\footnotetext{
1 Puede consultarse el libro "La resistencia como máscara del deseo" (Lombardi, 1991), para comprender los efectos de esa reducción típica del post-freudismo, que el autor llama "interpretación forzada" y "codificación pulsional del deseo".
} 
todo y después se iluminó" en 15) y también presencia de verbos relativos a acciones físicas que aparecen vinculadas a lo oscuro y lo iluminado ("entré y me mandé a la oscuridad corriendo" en 7 , "entramos a una ciudad bien iluminada" en 10).

Estas construcciones, relativas a la acción, poseen especial importancia para el psicoanálisis lacaniano, a partir de la postulación del "acto" como modo privilegiado de elección subjetiva, cuyas características principales son: el actuar no calculado, no programado, la asunción de cierto riesgo, la transgresión de algún límite y la modificación de la posición subjetiva como consecuencia de cada acto.

La vinculación del acto con la palabra es primordial y debe su origen a la teoría lingüística de los actos de habla, que fue ampliada por Lacan para el campo psicoanalítico hasta definir al acto como "un decir a partir del cual el sujeto cambia" (1969/2012: 395).

Por lo tanto, en psicoanálisis el acto concierne también al campo de las elecciones y decisiones que toma un sujeto a lo largo de su vida, saliendo de la indeterminación en que se encuentra inmerso en tanto sujeto dividido por la duda, la insatisfacción o el temor.

Como puede apreciarse, en ambas series de sueños la representación imaginaria del acto es abundante: en P., vehiculizada en los verbos "entrar" e "iluminar", y en A. en "nadar", "sumergirse", "meterse", "tirarse".

En el caso de P., y tal como él lo señala a raíz de uno de sus primeros sueños, todo esto lo lleva a "la duda sexual". Se escucha como telón de fondo un miedo a la homosexualidad que no sorprende a ningún psicoanalista, aún cuando se presenta en sujetos con una elección de pareja heterosexual y que consideran no sentir atracción por su mismo sexo. En todo caso, hay un dilema que se plantea a nivel ontológico (sumamente frecuente en la neurosis obsesiva): más se cree que hay "dos zonas bien diferenciadas" (como en el sueño 8), más se duda respecto a cuál de ellas el sujeto pertenece, ya que, como lo anunció 
Lacan hace tiempo, "no hay ningún medio para decir en qué dosis son ustedes masculino o femenino" (Lacan, 1966-1967). En todo caso, se trata de una cuestión de elección.

Teniendo en cuenta esta orientación teórica, que forma parte de la dirección de la cura propuesta por Lacan (hacia la inconsistencia del Otro y, por lo tanto, la confrontación con la elección), cobran relevancia algunos elementos de los sueños de P. cuya pertenencia semántica los ubica:

- $\quad$ en el terreno de lo indefinido (la construcción verbal "yo estaba sobre un borde" en 13, y las nominaciones "androide" en 2, "anfibio" en 8, "una respuesta de mediocridad" en 16 y "luz incandescente" en 20);

- o bien de lo que es capaz de fluir de un polo a otro ("hay una inversión" en 5, "se transformó" en 8 , "Renault Fluence" en 10);

- también todo lo que puede interpretarse como agujero en el sentido ("se abrian grietas en el piso" en 3, "un tajo, una herida grande" en 4, "una gotera enorme" en 11);

- y lo que simboliza la sacudida de la creencia en la completitud del Otro ("ahí se muere. Se desvaneció" en 4, "un caos, una crisis, todo se estaba desvaneciendo", "un sacudón" en 5, "se caía y se rompía algo" en 13).

Como puede apreciarse, corresponden tanto a subjetivemas verbales como nominales, pero su importancia se deduce, en primera instancia, a partir de los verbos que señalan las acciones cruciales.

A todos estos aspectos, los denominamos "castración", retomando el término freudiano, pero modificando su sentido habitual. Entendemos como castración todo aquello que apunta a la inconsistencia o incompletud del universo de 
discurso $^{2}$. En el sueño 9, encontramos una representación imaginaria de este efecto de castración sobre el sujeto: "un tipo en silla de ruedas, sin piernas y ciego".

Por otro lado, en los sueños de A. encontramos una serie de verbos que consideramos subjetivemas debido a su vinculación con aquello que la angustia y por la diversa posición que adquiere como hablante frente a eso, según las acciones que nombra.

Ya en el relato del primer sueño, ella señala una posición recurrente en sus sueños con el mar: "[siempre] me atrapa el mar, pero termino saliendo. Me escapo o corro".

Para mostrar los cambios que sufre esa posición a lo largo de la serie de sueños, nos serviremos de verbos que hayan sido conjugados tanto en primera como en tercera persona, y explicaremos en el siguiente apartado los motivos por los cuales tomaremos esos casos indistintamente.

En primer lugar, cabe subrayar la insistente aparición de los verbos "ver" y "mirar" en casi todos los sueños, siempre en primera persona. Son dos verbos que corresponden a una actividad pulsional que Lacan puso de relieve al agregar a los objetos libidinales freudianos (oral y anal) otros dos: voz y mirada. Por lo tanto, en los sueños de A. podemos leer el modo en que su lazo con el agua es mediado por la actividad de "mirar" y especialmente, "ver a lo lejos". Encontramos, por ejemplo, "estaba contenta de verlo lindo" (en 4), "yo lo miraba, me llamaba la atención" (en 5), "nunca vi el mar" (en 6), "yo estaba como apreciando eso, como una foto" (en 12), "veía un video" (en 14), entre muchos otros.

Por otra parte, subrayamos del sueño 2 los verbos "flotar" (también en 10 y 13) y "agarrarse". En 4, destacamos "protegerse" y "hundirse"; en 5, "pescar" y "sacar" (dos verbos que ella asocia con el "analizarse", con el buscar recuerdos

${ }^{2}$ Y decimos, a partir de cierta etapa de la enseñanza de Lacan, que no conforma un universo, debido a su incompletitud estructural. Véase al respecto "El no-todo de Lacan" (Le Gaufey, 2007). 
y asociaciones a partir de sus sueños); en 11 y 13, "pasar (la ola)"; en 16, "nadar", "jugar" y "querer cruzar"; en 17, "estar sumergida", "esconderse", "engañar" y "agarrarse". Obsérvese que en ese último sueño, aparecen verbos que implican por su significado un obstáculo a la mirada (tanto "engañar" y "esconderse" como "estar sumergida"), lo cual, en este contexto, puede leerse como un avance (y un alivio para esta analizante, constantemente incómoda por la mirada del Otro).

A partir de los subjetivemas verbales, podemos reconstruir, entonces, el sentido de las transformaciones sucesivas observables en estos relatos oníricos, cuyo avance se orienta hacia la atenuación de las dicotomías, con un efecto positivo en cuanto a la posibilidad de actuar del sujeto.

\section{Inscripción de las personas en el discurso}

De acuerdo con Benveniste, toda situación de enunciación implicará la emergencia de indicios de persona (yo-tú), que sitúan los lugares respectivos de locutor y alocutario. "La presencia del locutor en su enunciación hace que cada instancia de discurso constituya un centro de referencia interna. Esta situación se manifestará por un juego de formas específicas cuya función es poner al locutor en relación constante y necesaria con su enunciación" (Benveniste, 1966/2008: 85).

Ahora bien, si el yo y el tú pueden constituirse como elementos deícticos del discurso y, por lo tanto, formas vacías que no refieren más que a quien participa de la situación de enunciación en ese momento, pudiendo ser llenadas por otros interlocutores en otro contexto, no sucede lo mismo con la tercera persona.

Como dijimos anteriormente, en la lectura psicoanalítica de un sueño no hacemos distinción entre aquello que se presenta en tercera persona y aquello que es asumido por la primera. Esto obedece a razones de tradición psicoanalítica y comprobación clínica hasta la actualidad. Partimos de la propuesta de Freud de que todos los sueños "son absolutamente egoístas, en 
todos ellos emerge el querido yo" (Freud, 1900/2001: 276), que puede figurar varias veces en un mismo sueño, "una vez directamente, y otras por medio de la identificación con personas extrañas" (Ibíd.: 328).

Por lo tanto, aquello que se predica sobre terceros en un sueño, puede interpretarse directamente como referido al yo. Incluso respecto a los sueños enteramente narrados en tercera persona, cabe concluir: "toda vez que en el contenido onírico no se presenta mi yo, sino sólo una persona extraña, tengo derecho a suponer tranquilamente que mi yo se ocultó tras esa persona, por identificación" (Ibíd.: 328).

Es interesante tomar en consideración la concepción de Benveniste al respecto, quien advierte que con la tercera persona se activa el mundo de la referencia; la tercera persona es, de alguna manera, una no-persona en el discurso. Puesto que la situación de enunciación involucra solamente al yo y al tú, la tercera persona no entra en juego sino como objeto referencial.

A nuestro parecer, desde esta concepción de Benveniste hasta la tesis lacaniana de que el sujeto es objeto en su fantasma, hay un solo paso. La observación de Benveniste es aquí iluminadora, porque decimos en psicoanálisis que el inconsciente "habla" en tercera persona y, como se muestra magistralmente en los sueños, ese sobre quién predica el yo, no es otro que el sujeto mismo, aunque en su faceta de objeto. El psicoanálisis ofrece una explicación para este trastrocamiento del orden lingüístico en el inconsciente: es que el sujeto, tal como es pensado en la teoría de Lacan, no puede decir "yo", no puede tomar a su cargo el ser. El sujeto lacaniano es antes bien un efecto, tal como el efecto de significación, y por lo tanto, evanescente.

Por consiguiente, si revisamos nuestro corpus de análisis con esta clave, encontraremos que los sueños de P. involucran tanto a la primera como a la tercera persona, con apenas una mención a la segunda (en las asociaciones del sueño 5), que se presenta complejamente: "la rubia podés ser vos, pero hay una inversión [...] Puede ser que en el sueño esté invertido eso, vos me sacudías a 
mí para que reaccione". Es decir que la segunda persona, cuando aparece, lo hace en espejo, recibiendo pasivamente la acción que más tarde el analizante le adjudicará. Representa, por lo tanto, también a la primera persona. Nótese que la utilización de "invertido" para explicar ese recurso del sueño, alude también vía el sentido a la problemática en juego para este analizante, que mencionábamos anteriormente.

Si consideramos la serie completa de sueños de ambos analizantes, podemos decir que predomina el uso de la primera persona, aunque con presencia de la tercera, cuya función es necesario despejar en el análisis de cada sueño en sesión (partiendo de las asociaciones del soñante, que aquí no trabajaremos), ya que alli hay pensamientos que no han sido asumidos por el soñante y que pueden pasar desapercibidos si no son puestos de relieve por el analista.

Esto puede observarse, por ejemplo, en lo que se predica sobre el gato en el sueño 2 de P.: "raro", "como una prostituta", "androide", "gato puto". También en los sueños de A. a través de la gente que pesca (en 5), el barco que se hunde y el barco que avanza con ruedas (en 6 y 7), las "personas que tenían el agua hasta las piernas" (en 9) y las personas que intentan cruzar hasta un extremo inalcanzable, en 16 (problemática que ocupa su discurso frecuentemente).

Para cada uno de esos elementos y las acciones que se les atribuyen, podemos suponer una identificación del sujeto que ha sido desfigurada por la plasmación onírica en forma de escena, con reparto de roles, pero que una vez interrogada como construcción discursiva, muestra su afinidad con los pensamientos del analizante y con las acciones y cualidades que competen a la primera persona.

\section{Actitud de locución}

Utilizaremos aquí la propuesta de Weinrich (1974), de agrupar los tiempos verbales en dos grandes categorias: narración y comentario, para reconocer y ubicar la actitud de locución que predomina en el corpus de análisis y los efectos de sentido. 
La situación narrativa se caracteriza por presentar los sucesos con cierta distancia, restando dramatismo y manteniendo cierta relajación en la situación de enunciación. La situación comentadora, en cambio, está cargada de dramatismo, ya que presenta los hechos como afectando directamente a la situación discursiva actual y comprometiendo al hablante en la misma.

En todo nuestro corpus de análisis encontramos una clara predominancia del mundo narrado, con verbos en pretérito imperfecto, que ubican casi todos los sucesos en un momento anterior: el del transcurso del sueño, donde las acciones forman parte de una escena fantaseada. A su vez, el uso recurrente del "había" los acerca al estilo narrativo del cuento popular.

No obstante, son de destacar las apariciones de algunos verbos en pretérito perfecto simple, que funcionan como incrustaciones o "metáforas temporales" (Weinrich, 1974), acortando la distancia entre la situación de enunciación y el tiempo en que transcurrió el sueño -subrayamos en el corpus las apariciones de verbos en presente y en pretérito perfecto simple, para otorgarles visibilidad, puesto que el tiempo verbal predominante es el pretérito imperfecto-. De ellas extraemos el efecto de continuidad entre este último y el presente de la situación discursiva, que marca la existencia de una afectación actual por aquello sucedido en la escena onírica.

También cabe considerar esas transiciones entre pretérito imperfecto y perfecto simple, en función del "relieve narrativo, que permite distinguir entre un primer y un segundo plano, entre lo que es fundamental o accesorio" (Beltramino \& Verardi, 2007: 163).

En P., los sueños 4 y 14 son los que presentan en mayor medida esta incrustación del perfecto simple, y se nota rápidamente que producen un efecto de sentido ligado a lo que urge, a la relevancia crucial de lo sucedido y a la importancia de relatarlo. Similar es el caso de los sueños 5, 6, y 10, donde una única aparición del pretérito perfecto simple marca todo el relato, poniendo una acción de relieve por sobre otras, muy variadas. 
Nos parece importante destacar la coincidencia entre el uso de ese tiempo verbal y la relevancia de las acciones de que se trata en cada caso. Es decir, en cada uno de esos cambios de registro hay acciones que son puestas de relieve y justamente no se trata de acciones triviales, sino sumamente importantes, ligadas al acto.

En ese sentido, del sueño 5 subrayamos la expresión "puse un poco de razón", del 6 "entré y me mandé a la oscuridad corriendo" y del 10 "entramos a una ciudad bien iluminada. Sentí algo agradable". Todos aluden a cambios; metaforizan la entrada en una nueva posición subjetiva (con la necesaria asunción del riesgo implicado en todo cambio, que tanto nos asusta a los neuróticos).

También es de destacar el uso del presente en el sueño 11: "en el sueño me despierto y veo una gotera enorme". Consideramos que esta mención hecha en presente, con valor de presente histórico, debe destacarse en el marco de otras acciones de ese mismo sueño, narradas en tiempo pretérito imperfecto. Es interesante reparar en que ese sueño, que en realidad son dos sueños de una misma noche, relata el encuentro con un libro acerca de "la historia de las elecciones", así como de la "buena elección" de un farol fabricado con un papel especial. En ese contexto, la aparición del tiempo presente para relatar el despertar que ocurría dentro del sueño, puede interpretarse como un acercamiento al registro subjetivo en que ocurre la elección: el del acto, único caso en que Lacan reconoce a un significante estar tan cerca como es posible de significarse a sí mismo (1966-1967).

Respecto a los sueños de A. cabe señalar que los dos primeros constan de varios verbos en presente, porque ella se encuentra comentando una situación recurrente, algo que se repite en sus sueños desde tiempo atrás. Lo mismo sucede con un pensamiento dentro del sueño 4, que alude a la continuidad/discontinuidad entre los sueños previos y el actual (Pensé "ya no es líquido, no te hundís si pisás”). El hecho de que ella registre el encadenamiento que ocurre entre algunos de sus productos oníricos, le permite 
señalar diferencias y novedades; cuando lo hace, utiliza el pretérito perfecto simple, como en 6 ("Nunca vi el mar") o 10 ("Siempre estoy arriba").

También encontramos importantes puestas en relieve en 6, 11, 13 y 16, donde A. introduce el pretérito imperfecto para marcar el peso de ciertas acciones oníricas ("se empezó a hundir", "salió", "la vi venir y la pasé", "traté de flotar", "nadé"). Del mismo modo, le otorga actualidad a algunos elementos por sobre otros mediante el uso del tiempo presente ("mi tía me dice", en 13, por ejemplo).

Al igual que en el caso de P., consideramos que estamos frente a acciones principales, destacadas por su relevancia y cercanía con la posición subjetiva actual del analizante y opuestas a las referidas en pretérito imperfecto, que constituyen más bien el telón de fondo del relato.

\section{Conclusiones}

En este análisis discursivo parcial, limitado a algunas categorias por nosotros seleccionadas, hemos podido apreciar diversas transformaciones enunciativas a lo largo de una serie de relatos oníricos, del estilo continued story, de dos analizantes diferentes.

Nos hemos limitado a un análisis de las formas, en detrimento de las posibilidades infinitas de interpretación de los contenidos, siguiendo la propuesta lacaniana de dirigir todo análisis hacia la extracción de elementos invariantes, en lugar de priorizar las derivas del sentido. En esta labor, el análisis del discurso ha operado como instrumento metodológico privilegiado, permitiendo la detección de modos particulares de articulación de ciertas categorias enunciativas, que de otra manera permanecerian invisibles.

Lo analizado nos permite afirmar que, aunque el AD esté habitualmente orientado a la articulación con lo social (Arnoux, 2006), también constituye una herramienta valiosa para otros campos de saber -en este caso el psi-, especialmente allí donde se vuelve necesario un abordaje que respete la complejidad de los fenómenos. Es así que el $\mathrm{AD}$ se ha mostrado como una 
metodología de análisis familiar a esta disciplina, cuyo objeto de estudio está en intima relación con lo discursivo, pero también diferente y enriquecedora. El mejor ejemplo lo aporta la diferencia entre mundo narrado y mundo comentado, en los que el psicoanalista no repararía habitualmente, pero que constituye un recurso usual del AD. Y el psicoanálisis, por su parte, ofrece observaciones -como la de la identidad entre primera y tercera persona- que pueden resultar enriquecedoras para el $\mathrm{AD}$ aplicado a cualquier otro campo disciplinar.

\section{Anexo: Corpus de análisis}

P., de 29 años

1. "De chico soñaba con mitos urbanos, como "La Llorona" y con la oscuridad."

2. "Soñé que estaba peleando con androides que entraban en casa. Había una chica y un chico. Como los androides estaban escondidos en una habitación, a oscuras, la chica tiraba un fósforo para iluminar y el chico le tiraba tiros al androide. Estábamos hablando en la puerta de mi pieza. Después aparecíamos en el pasillo y había un gato en la azotea y alguien decía "mirá el gato, es raro". Me daba a entender que el gato era como una prostituta, no sé, era muy raro el sueño. Después era como que el gato era androide, pero al final era mi gato". En las asociaciones: "a ese gato yo siempre lo abrazaba y le decía "gato puto". Todo me lleva a la duda sexual."

3. "Soné que quería prender una luz, pero no se prendía. Había una oscuridad densa. Me acordé de un sueño que tuve cuando era chico. Se abrian grietas en el piso, había trampas para osos en una calle de tierra. Estaba todo oscuro."

4. "Soñé que estaba en el departamento de mi tía. Era de noche, estaba todo oscuro. Mi gato negro saltaba de un balcón a otro y se lastimaba. Tenía como un tajo, una herida grande. Empezó a chillar muy fuerte y yo me puse 
nervioso. Después me preocupé porque había desaparecido, hasta que to encontraba y estaba como sin pelo, sarnoso, y ahí se muere. Se desvaneció." 5. "Soñé que estaba en Y (ciudad en la que vivió) y ocurría un caos, una crisis, todo se estaba desvaneciendo. Yo estaba en una plaza, había árboles y arbustos oscuros y no sabía qué había ahí, si había peligro o no. Estaba toda oscura la plaza. Había una chica rubia que estaba histérica. Yo la agarraba y la sacudia por los hombros y le decía que se calme, puse un poco de razón." (Para este fragmento del sueño, P. propone una interpretación inmediata: "la rubia podés ser vos, pero hay una inversión, porque yo el año pasado estuve histérico, se me juntó todo. Nunca pensé que me iba a pasar eso de desbordarme así. Y cuando empecé a venir acá fue como un sacudón; empecé a pensar. Puede ser que en el sueño esté invertido eso, vos me sacudías a mí para que reaccione").

6. "Soñé que estaba en la casa de mi abuela y la puerta que comunicaba a la casa antigua, la que está abandonada, se abría. Entré y me mandé a la oscuridad corriendo. Quise vencerlo. Ahí me desperté."

7. "Soñé que estaba en X (su ciudad de origen), en la casa de mi abuela. Volví a soñar con R. (su ex novia), pero también con su hermana. Estábamos en una habitación. Yo salía, pasaba al comedor y encontraba la puerta abierta esperándome y la oscuridad. Después mi pieza era la de mi abuela y yo estaba durmiendo. R. venía a buscar no me acuerdo qué, ropa, creo. Yo le estaba haciendo un favor. Dejaba una carta que decía "Gracias por todo. Un último favor" y firmaba con garabatos (risas): eran Tom y Jerry y otro dibujito, Bender. La firma estaba hecha como la de un nene de 10 años".

8. "Soñé que había dos planos y se notaba bien la diferencia: una zona iluminada, con alta resolución, bien definida y otra oscura. Era la casa de mi abuela. Estaba mi hermano. El piso rojo se transformó en amarillo y dorado con rojo. Yo miraba a través de una persiana americana. Después salía a la calle. Veía edificios antiguos con balcón y en el cielo, la cara de Zeus. Como que todo era muy barroco. Había muchos edificios iguales, de distintos colores. Se veía el cielo celeste claro. En un lugar había una boca de tormenta, en un 
edificio bien oscuro. Yo caminaba con una compañera. Mi hermano se la quería levantar. Yo tenía el anillo de casado de mi hermano. Veía una telaraña y una araña en mi hombro. Después aparecía nadando en una pileta, siendo chiquito, con un compañero de la facultad. Yo era como un anfibio, como que podía andar por la tierra y por el agua."

9. "Soñé que caminaba por acá, por el centro. Había un tipo en silla de ruedas, sin piernas y ciego."

10. "Soñé que íbamos en un auto negro, un Renault Fluence. Mi viejo iba manejando y yo al costado, durmiendo. Estaba mi hermano y una chica que era la mezcla de varias chicas. En un momento, entramos a una ciudad bien iluminada. Sentí algo agradable, como que estaba realizando algo".

11. "Tuve un sueño bastante raro. Era en un lugar de antigüedades. Yo me ponía a mirar un farol que le faltaba la luz. El vendedor era un tipo canoso. Me contaba que estaba hecho de un papel árabe. Como que me dijo "buena elección". En el sueño estaba todo nublado, tipo sepia. Veía un libro grande de matemáticas, de cuero marrón, que hablaba de la historia de la elección. Después íbamos caminando con un tipo y unas chicas y tomábamos un colectivo." Misma noche: "estaba todo oscuro y lloviendo. En el sueño me despierto y veo una gotera enorme."

12. "Un sueño raro. Lo oscuro a lo lejos me agarraba. Eran dos sueños. En el primero estaba inmerso en la oscuridad. En el segundo me asfixiaba, no me dejaba respirar."

13. "Tuve dos sueños reveladores. En uno, estaba en la playa con mi familia. El mar se veía raro, había vórtices, remolinos oscuros. Después yo estaba sobre un borde, en la arena, mis viejos sentados y los nenes jugando alrededor. $\underline{\mathrm{Me}}$

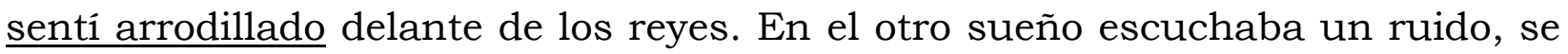
rompía algo. Se caía y se rompía algo de vidrio o de metal. Eso me despertó". 14. "Tuve un sueño donde yo tenía una actitud jovial, era chico o de esta edad. Veo por la ventana que en la calle había una fiesta, transcurría una vida y yo la estaba mirando. Se oscureció todo y después se iluminó”. 
15. "Tuve un sueño en unos montículos de arena donde jugaba de chico. Estaba con un amigo. Él estaba como haciendo terreno ahí. Él era piloto y yo copiloto. Después, con otro amigo íbamos viajando y agarrábamos un atajo: un túnel todo negro, como de barro."

16. "Soñé que yo estaba luchando por un lugar, peleándola. Había una persona con rasgos de mi hermano y de un compañero de la escuela (que se burlaba de mi cuando era chico). Era como en un jardín, como un patio interno, todo de vidrio, lo asocio con una cajita de cristal, muy iluminado. Yo estaba entrando, pasando una puerta, era propio, mío. Yo estaba luchándola, firme pero calmo. Esa persona me daba una respuesta de mediocridad. Me decía: 7."

17. "Soñé que estaba en lo de mi abuela. Había una reunión y había jugadores de fútbol. Yo estaba dando comentarios, como una conferencia de prensa. Aparecía mi tía, que se quería levantar a Verón (risas). Pero estaba más llena de vida, no triste como está siempre. A los costados estaba todo oscuro, alrededor de la sala. Se veía lo oscuro por las ventanas."

18. "Me acordé de algo que soñaba de chico. Siempre había un ente en la oscuridad, con manos, que me queria agarrar. Yo lo iba a enfrentar, pero me dejaba agarrar, cedía o me iba corriendo, pero no lo enfrentaba".

19. "Hoy soñé con una ciudad que venía una nube negra, como un anillo que la bordeaba. En el medio se abría un espacio de luz. Yo estaba caminando, interactuando con personas, hablando con mi viejo y mi sobrina."

20. "Soñé que estaba en la casa de arriba del negocio de mis viejos. Yo sostenía una tabla de surf o un celular gigante (como siempre mi vieja me jode por celular...). Me estaba como retando. Primero pasaba por el cuarto de mi mamá, que estaba todo oscuro, al mío, que estaba más iluminado. Había una luz incandescente, amarilla, como en las películas de terror, y una pared llena de posters."

A., de 30 años 
1. "Siempre sueño con el mar de noche. El agua sucia, marrón. Me atrapa el mar, pero termino saliendo. Me escapo o corro."

2. "Tuve un sueño distinto esta semana. El mar era celeste. Había maderas flotando, yo me agarraba de las maderas para tener la cabeza afuera. No veía la orilla. Era distinto porque siempre estoy cerca de la orilla y el agua es sucia y oscura."

3. "Soñé que estaba en una casa de dos pisos, arriba, como que era la ventana de mi pieza. Se veía el mar celeste, con olas, a lo lejos. Estaba contenta de verlo lindo."

4. "Soñé que estaba como en una islita, como en una montañita, como protegiéndome de lo que está abajo, que era como pasto. Pensé "ya no es liquido, no te hundís si pisás"."

5. "Soñé que estaba en la plataforma en la parte de atrás de un barco. Habia gente al borde, pescando. Sacaban un pescado grande y lo mostraban. Era gris, grandote y gordo. Yo lo miraba, me llamaba la atención."

6. Dos sueños de una misma noche. Primero: "Soñé que iba de viaje, de noche, por un camino angosto con líneas amarillas. Doblaba con el auto, el espacio era muy chiquitito. Iba a la costa. Estaba mi ex con los padres. Nunca vi el mar. Seguía de noche (como en otros sueños). Le decía que no sentía nada por él". Segundo: "Soñé que el agua era celeste, pero algo también tenía, como sucio. Había un barco y arriba, gente. Se empezó a hundir. Yo miraba desde la costa. Salió una ballena de dientes grandes, como colmillos."

7. "Soñé que era de noche. Yo estaba arriba de algo, no sé si era alguna bajada tipo para patinar. Había gente tirándose, con dos tipos de rollers. Unos tenían las rueditas en línea; y otros, rueditas y un arco. Esos era como que se deslizaban; el arco protegía las ruedas, que estaban inmóviles, no giraban. Después veo un barco, pero no en el agua... ¡tenía ruedas! (risas), iba por la calle y había gente, era como una despedida."

8. "Soñé con piletones de agua sucia y gente metida. Yo no quería meterme, porque la veía marrón." 
9. "Soné que no estaba en el agua, pero veía personas que tenían el agua hasta las piernas. No sé si era mar..."

10. "Soné que estábamos comiendo afuera, creo que estaba mi hermana, y llovian estrellas, se empezaban a caer. Yo tenía que viajar a tomar un avión. Llegaba a unas montañas, como una... ¿"colina" se dice? Veía el mar celeste y una persona en el agua transparente. El cuerpo se veía, porque no era profundo. Había dos peces, delfines, creo, eran raros, tenían una crestita blanda arriba, como los peces. Iban flotando, como livianos. Era como que yo me lamentaba de no poder ir al agua. Siempre estoy arriba."

11. "Soñé que estaba en el mar, había olas marrones y había caracoles tipo tirabuzón. Yo los quería agarrar. La ola estaba de frente y la pasaba. La vi venir y la pasé."

12. "Soñé que veía a la distancia el mar y montañas. Yo estaba como apreciando eso, como una foto, como que está lejos. El paisaje era chiquito. Con la hermana de X (su novio) alquilábamos patines. Había una subida. Nos cobraban 10 pesos y nos devolvian 5, pero nos cagaban, porque no nos daban los patines."

13. "Soñé con Brasil. Había montañas y dos personas: mi tía y alguien más, no sé si mi mamá. Estábamos de vacaciones. El sueño era un poco oscuro, como color sepia. Había una fiesta en un barco, con una barra de madera rústica. Yo veía un almanaque con el 42 o el 26 marcado, porque iba a haber una excursión ese día. Yo no iba a estar para ir a la excursión. Después veía el agua entre dos montañas. A lo lejos se veía el mar abierto, con olas. Mi tía me dice que no me asuste. Traté de flotar. Venía una ola grande y mi tía me dice que me meta abajo para pasarla y la pasé."

14. "Soñé que estaba buscando lugares para ir de vacaciones en Brasil. Veía un video donde había montañas y el mar a lo lejos, era como un lugar histórico, con una entrada como la de Parque Pereyra. Había una carrera de bicicletas viejas, de esas con volante redondito. Eran muchos. Un cartel decía: "un real". Las letras eran como palitos, como letras chinas." 
15. "Soñé que mi hermana me sacaba una camperita a cuadros para salir. Veía montañas, pero de tierra, no eran de arena ni rocosas, medio marrones. Y en el medio había muy poquita agua. Lo distinto es que eran colores más vivos."

16. "Soñé con un lago entre montañitas de tierra. Yo estaba nadando. Era un ambiente de amigos, estaba P. (una amiga) en una orilla. Nadé un poquito, sin mirarme los pies y con la cabeza afuera. Iba mirando que jugando no me quisieran hundir. Venían dos micros de dos pisos, querian cruzar al otro extremo, que era más alto, pero por el agua. Unas personas querían agarrar el colectivo y tirarlo hasta arriba, pero se caía. En el extremo alto estaba E. (un ex novio). Nunca iban a poder cruzar, porque el otro extremo era más alto".

17. "Tuve un sueño en el agua, era una montaña abajo del agua y yo estaba sumergida con alguien más. Yo tenía un disfraz de pez, para esconderme o engañar a otros peces. Estaba agarrada de una roca verde brilloso."

\section{Referencias}

Arnoux, E. (2006) El análisis del discurso como campo interdisciplinario. En Análisis del discurso. Modos de abordar materiales de archivo. Buenos Aires: Santiago Arcos Editor.

Bally, C. (1940) L'arbitraire du signe. Valeur et signification. Le française moderne, 8, 193-206.

Beltramino, F. \& Verardi, M. (2007) Verbo y situación comunicativa: los tiempos más allá del tiempo. En Metodologías cualitativas en ciencias sociales. Buenos Aires: Biblos.

Benveniste, E. (1966/2008) Problemas de Lingüística General (Vol. 1 y 2). México: Siglo XXI.

Charaudeau, P. (2000). Las problemáticas de base de una lingüística del discurso. En Lengua, Discurso, Texto. I simposio Internacional de Análisis del Discurso (págs. 40-51). Madrid: Visor.

Freud, S. (1900/2001). La interpretación de los sueños. En Obras Completas (Vol. 4 y 5). Buenos Aires: Amorrortu. 
Ghio, A. (2012) El léxico en la polémica. En Giammatteo, M. \& Albano, H. El léxico: de la vida cotidiana a la comunicación cibernética. Buenos Aires: Biblos.

Kerbrat-Orecchioni, C. (1986/1997) La enunciación. De la subjetividad en el lenguaje. Buenos Aires: Edicial.

Lacan, J. (1966-1967) La lógica del fantasma. Inédito. Versión de la Escuela Freudiana de Buenos Aires.

Lacan, J. (1959-60/2007) La ética del psicoanálisis. Buenos Aires: Paidós.

Lacan, J. (1975-76/2009) El sinthome. Buenos Aires: Paidós.

Lacan, J. (1967/2012) Proposición del 9 de octubre de 1967 sobre el psicoanalista de la escuela. En Otros Escritos (p. 261-277). Buenos Aires: Paidós.

Lacan, J. (1969/2012) El acto psicoanalítico. En Otros Escritos (p. 395-403). Buenos Aires: Paidós.

Le Gaufey, G. (2007). El no-todo de Lacan. Buenos Aires: El cuenco de plata.

Lombardi, G. (1991) La resistencia como máscara del deseo. Buenos Aires: Puntosur.

Weinrich, H. (1974) Estructura y función de los tiempos en el lenguaje. Madrid: Gredos. 